\title{
Amish lethal microcephaly
}

INSERM

\section{Source}

INSERM. (1999). Orphanet: an online rare disease and orphan drug data base. Amish lethal microcephaly. ORPHA:99742

Amish lethal microcephaly is a very rare syndrome characterized by extreme microcephaly and early death, within the first year. 